\title{
(6) OPEN ACCESS \\ Kinetics of versican-expressing macrophages in bone marrow after cord blood stem cell transplantation for treatment of acute myelogenous leukaemia
}

\author{
Miho Senda, ${ }^{1,2}$ Ryuichi Fukuyama, ${ }^{3}$ Tetsuro Nagasaka ${ }^{2}$
}

\section{- Additional material is published online only. To view please visit the journal online (http://dx.doi.org/10.1136/ jclinpath-2015-203496). \\ ${ }^{1}$ Department of Clinical Laboratory, Konan Kosei Hospital, Aichi, Japan ${ }^{2}$ Department of Medical Technology, Nagoya University Graduate School of Medicine, Aichi, Japan \\ ${ }^{3}$ Department of Diagnostic Pathology, Konan Kosei Hospital, Aichi, Japan}

\section{Correspondence to} Miho Senda, Department of Clinical Laboratory, Konan Kosei Hospital, 137 Ohmatsubara, Takaya, Konan, Aichi 483-8704, Japan; patho@konan.jaaikosei.or.jp

Received 2 November 2015 Revised 31 January 2016 Accepted 9 February 2016 Published Online First 7 March 2016
CrossMark

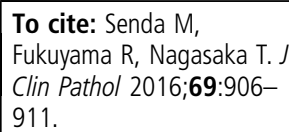

\section{ABSTRACT}

Aims To determine versican-producing cells in normocellular bone marrow and to evaluate chronological alteration in the number of versicanproducing macrophages in bone marrow of patients with acute myelogenous leukaemia (AML) after cord blood stem cell transplantation (CBSCT) to gain insight in the significance of versican in recovery of haematopoiesis. Methods We enrolled seven age-matched unrelated patients with normocellular bone marrow for determining versican-producing cells in bone marrow, CBSCT-treated patients with AML, 18 with fine and other four with poor engraftment, for determining chronological alteration of versican-expressing and CD68-expressing cells in transplanted bone marrow in reference to the total cells. Clot samples of patients with AML were collected from the +16 to +55 day after transplantation and separated into four groups. We included an AML case whose specimen was obtained on the +9 day. Cells positive in immunohistochemistry using antibodies to versican and CD68 were counted to obtain the mean $\pm S D$ in a unit area of the bone marrow, plotted chronologically and compared with the numbers from the age-matched normocellular group.

Results We determined by a double immunohistochemistry that the versican-expressing cells in bone marrow are macrophages. The time-course curve demonstrated an inverse relationship between the versican-positive macrophages and the total cells in the transplanted bone marrow for over 55 days. In bone marrow of poor engraftment cases, versican-positive macrophages appeared to be decreased in comparison with age-matched and sampling day-matched patients.

Conclusions These results suggest that versican and/or versican-expressing macrophages positively contribute to bone marrow regeneration of patients with AML after CBSCT.

\section{INTRODUCTION}

Versican/PG-M is a type of large chondroitin sulfate proteoglycan belonging to the aggrecan family, and plays important roles in cell adhesion, migration and differentiation as a molecule of extracellular matrix (ECM). ${ }^{1-4}$ Versican is first identified in culture medium of fibroblasts ${ }^{5}$ and its wide-range distribution is subsequently revealed in the smooth muscle cells, ${ }^{6} 7$ cartilage, ${ }^{8} \operatorname{skin}^{9}$ and blood vessels. ${ }^{10}$ Versican is also expressed at the ECM of malignant tumors ${ }^{11} 12$ and developing embryos. $^{10} 13$

The main cell type that produces versican in inflammatory lesions has been revealed to be macrophages. ${ }^{4}$ Many other reports also demonstrated that macrophages express versican and that it is overexpressed when they are activated by granulocyte-macrophage-colony-stimulating factor (GM-CSF), ${ }^{14}$ lipopolysaccharide ${ }^{15}$ and hypoxia. ${ }^{16}$ At ECM, it binds to hyaluronan and other ECM molecules such as fibronectin ${ }^{417}$ and several chemokines, ${ }^{18} 19$ thereby influencing leucocyte function.

Versican reportedly exists in the long-term culture of mouse bone marrow (BM) cells ${ }^{20}$ and in the ECM of BM after chemotherapy. ${ }^{21}$ Moreover, Oguri et $\mathrm{al}^{22}$ detected a large amount of proteoglycan with chondroitin 6-sulfate in rabbit BM tissues. Although versican in BM has not been analysed biochemically, proteoglycans at the ECM have been known as binding partners for humoral factors that activate haematopoietic progenitors. ${ }^{23}$ These reports support the hypothesis that versican may play an important role in the haematopoiesis of BM. Localisation of versican in BM tissue has been analysed immunohistochemically, yet the cells that produce versican in this tissue were not delineated.

Transplantation of cord blood (CB), BM and peripheral blood (PB) stem cells (SCs) has been performed for treatment of haematopoietic diseases such as leukaemia. Down these lines, Nagasaka et $a l^{21}$ showed that the versican level is increased in $\mathrm{BM}$ of patients who have undergone chemotherapy. Therefore, it is likely that versican in BM may positively influence haematopoiesis in tissue after transplantation. To date, no study has been conducted to elucidate versican's overexpression and role in transplanted BM.

The purpose of this study is to identify versicanproducing cells in normal BM and to shed light on the significance of versican in transplanted BM.

\section{PATIENTS AND METHODS \\ Patients}

To address the possible significance of versican in $\mathrm{BM}$ regeneration, we enrolled 18 patients with acute myelogenous leukaemia (AML) who underwent cord blood stem cell transplantation (CBSCT). As we obtained clot specimens from an AML case 3 times and from 3 AML cases 2 times, the total number of samples in the assessment was 23. Three different stem cell transplantation (SCT) procedures have been performed at our hospital, namely, CBSCT, BMSCT and PBSCT. CBSCT is our current standard procedure because the graft versus host defence is less pronounced with it, and only a part of human leucocytic antigens needs to be matched. ${ }^{24} 25$ Therefore, we confined our analysis to CBSCT-treated patients. Our preparative regimen for CBSCT was based on previous reports, 
which was recently summarised by Arai et $a l^{26}$ and was shown in table 1.

BM clot was collected from the +16 to +55 day after transplantation for routine cytological and pathological evaluation of engraftment. We separated patients into four groups based on the duration after transplantation as follows: 16-25, 26-35, 3645 and 46-55 days. We included a case, whose specimen was obtained at the +9 day to examine a cause of his high fever, because it likely shows a possible tendency of the number of versican-positive/CD68-positive macrophages in the early phase of the recovery. The breakdown of these samples is shown in table 2 .

According to the record, no patients experienced recurrence. We identified four other patients with AML who exhibited severe hypocellularity in BM about 3-5 weeks after CBSCT, likely showing engraftment failure. We analysed this agematched poor engraftment group in the same way and compared with the corresponding 16-25 and 26-35 groups (namely, age-matched and sampling day-matched control). To determine versican-expressing cells in BM, we selected seven patients whose BM was isolated for diagnostic purpose and was normocellular, and then clinicopathologically diagnosed not to have haematological and other significant diseases. We named this an age-matched normocellular group (table 1) and the numbers of the total cells, and versican-positive and CD68-positive cells were used as a baseline for the kinetics assessment. Informed consent was obtained from each patient and the protocol was approved by the ethical committee of Nagoya University.

\section{Immunohistochemistry}

All samples used in this study were formalin-fixed and paraffin-embedded. Several $4 \mu \mathrm{m}$-thick sections were cut from the paraffin blocks, and one was stained with H\&E for diagnostic purposes. In immunohistochemistry (IHC), antigen-bound antibodies were visualised using a kit (Bond Polymer Refine Detection, Leica Biosystems Newcastle, UK), and brown colour was developed with diaminobenzidine (DAB).

Since versican-expressing cells were found likely to be macrophages, we performed double IHC using antibodies to versican (Abcam, Cambridge, UK) and to CD68 (PG-M1; Dako, Glostrup, Denmark). We employed this CD68 antibody because it was used to label all macrophages in $\mathrm{BM}^{27}$ With this technique, after versican-bound antibody was visualised with a brown colour with DAB, anti-CD68 antibody was reacted to the tissue section, and coloured red using the Bond Polymer Refine Red Detection kit (Leica Biosystems, Newcastle, UK). Nuclei were counterstained by haematoxylin, and immunohistochemical stain was carried out by the automatic IHC device (Leica BOND-MAX, Leica Biosystems).

\section{Statistical analysis}

All BM samples were divided into four groups based on duration after transplantation, $16-25,26-35,36-45$ and 4655 days (table 2). After immunostaining, all cells, versican- positive cells and CD68-positive cells in a $0.15 \mathrm{~mm}^{2}$ area of several sections were counted, and the average number and SD of each group were obtained. These data were compared with either each other or those of the age-matched normocellular group (analysis of variance, Bonferroni's correction). Data of the age-matched poor engraftment group were compared with those from the age-matched and sampling day-matched control (Student's t test). We used a Stat View program (STAT View for Windows, V.5; SAS Institute, Cary, New Castle, USA) and significance was set at $\mathrm{p}<0.05$.

\section{RESULTS}

\section{Macrophages are the versican-producing cells in BM}

We selected patients who had no haematopoietic or significant systemic diseases for this purpose (table 2, age-matched normocellular group, figure 1A). Results of the single (figure $1 \mathrm{~B}, \mathrm{C}$ ) as well as double (figure 1D) IHC on BM clot samples with antiversican and anti-CD68 antibodies strongly supported the consideration that versican is produced, partially if not entirely, by macrophages residing at the tissue stroma.

\section{Kinetics of versican-producing macrophages in repopulating BM after CBSCT}

Average numbers and SD of total cells, versican-positive cells and CD68-positive cells at the unit area in clots from the agematched normocellular group were approximately 221, 6 and 13 cells $/ 0.15 \mathrm{~mm}^{2}$, respectively (figure $2 \mathrm{~A}-\mathrm{C}$, dotted horizontal bars). Then, BM clots of patients who underwent CBSCT were stained similarly and the total cells were counted and compared with those of this group (figure $2 \mathrm{~A}-\mathrm{C}$, closed marks). The total haematopoietic cells in BM after pretreatment and transplantation appeared to be decreased on the +9 day (figure $2 \mathrm{~A}$ ) and recovered in number already for the 16-25 day group. Though not statistically significant, the total cell number kept gradually increasing thereafter (figure 2A). A significant increase in the total cell number was observed for the 46-55 day group compared with the $16-25$ day group ("p $<0.05)$. On the contrary, the average number of versican-positive cells increased steeply in the 16-25 group to that of the age-matched normocellular group $\left({ }^{\# \#} \mathrm{p}<0.001\right.$, figure $\left.2 \mathrm{~B}\right)$, and then sharply decreased $(* * \mathrm{p}<0.01$, ***p $<0.001$, figure $2 \mathrm{~B})$ when the total cell number increased. The number of CD68-positive macrophages was unaltered for the first month but fell significantly to the agematched normocellular group in the 36-45 day group $\left({ }^{\# \#} \mathrm{p}<0.01\right.$, figure $\left.2 \mathrm{C}\right)$. The linearly regressed time-course curves of the number of the total and versican-positive cells are schematically shown in figure $2 \mathrm{D}$, demonstrating their inverse relationship over the examined period.

\section{Comparison of the poor engraftment group}

The total cell number of the BM in the age-matched poor engraftment group was approximately six times less than that of the control $(* * \mathrm{p}<0.001$, figure $3 \mathrm{~A})$. The number of versicanpositive cells appeared to be less than half that of the agematched and sampling day-matched control, yet it did not reach

Table 1 General conditioning regimen before and after transplantation of our hospital

\begin{tabular}{|c|c|c|c|c|c|c|c|c|c|c|c|c|}
\hline Day & -7 & -6 & -5 & -4 & -3 & -2 & -1 & 0 & +1 & +3 & +6 & +7 \\
\hline & TBI & TBI & $C A$ & $C A$ & $\mathrm{CY}$ & $\mathrm{CY}$ & Tacrolimus & $\begin{array}{l}\text { Transplantation } \\
2.4 \pm 0.5 \times 10^{7} / \mathrm{kg}\end{array}$ & MTX & MTX & MTX & G-CSF \\
\hline
\end{tabular}

CA, cytarabine; CY, cyclophosphamide; G-CSF, granulocyte-colony stimulating factor; MTX, methotrexate; TBI, total body irradiation. 
Table 2 Clinical data of patients enrolled in this study

\begin{tabular}{|c|c|c|c|c|c|}
\hline Case no. & Group & Days & Age & Sex & Diagnosis \\
\hline 1 & & 9 & 58 & $M$ & MDS/AML \\
\hline 2 & $16-25$ & 20 & 40 & M & $\mathrm{AML}$ \\
\hline 3 & & 22 & 59 & $F$ & MDS/AML \\
\hline 4 & & 23 & 57 & $\mathrm{~F}$ & $\mathrm{AML}$ \\
\hline \multirow[t]{2}{*}{5} & & 25 & 34 & $\mathrm{~F}$ & AML \\
\hline & & $23 \pm 2^{*}$ & $48 \pm 12 \dagger$ & & \\
\hline 6 & $26-35$ & 28 & 37 & M & AML \\
\hline 7 & & 28 & 49 & $\mathrm{~F}$ & AML \\
\hline 8 & & 29 & 43 & $\mathrm{~F}$ & AML \\
\hline 9 & & 29 & 54 & $M$ & AML \\
\hline 10 & & 33 & 44 & M & $A M L$ \\
\hline \multirow[t]{2}{*}{11} & & 34 & 55 & M & MDS/AML \\
\hline & & $30 \pm 3^{*}$ & $47 \pm 7 \dagger$ & & \\
\hline 12 & $36-45$ & 36 & 27 & $\mathrm{~F}$ & AML \\
\hline 13 & & 36 & 55 & M & AML \\
\hline 14 & & 36 & 59 & M & MDS/AML \\
\hline$\underline{15}$ & & 36 & 60 & $\mathrm{~F}$ & MDS/AML \\
\hline 16 & & 38 & 57 & $\mathrm{~F}$ & $\mathrm{AML}$ \\
\hline 17 & & 40 & 54 & M & AML \\
\hline 18 & & 41 & 55 & $\mathrm{~F}$ & AML \\
\hline \multirow[t]{2}{*}{19} & & 42 & 30 & M & AML \\
\hline & & $38 \pm 3^{*}$ & $50 \pm 13 \dagger$ & & \\
\hline$\underline{20}$ & $46-55$ & 50 & 54 & M & AML \\
\hline$\underline{21}$ & & 52 & 40 & $M$ & AML \\
\hline 22 & & 55 & 49 & $F$ & AML \\
\hline \multirow[t]{3}{*}{$\underline{23}$} & & 55 & 58 & $\mathrm{~F}$ & AML \\
\hline & & $53 \pm 2^{*}$ & $50 \pm 8 \dagger$ & & \\
\hline & Age-ma & d poor en & ftment gr & & \\
\hline 1 & Poor & 20 & 30 & $M$ & AML \\
\hline 2 & & 21 & 31 & $\mathrm{~F}$ & AML \\
\hline 3 & & 26 & 55 & M & AML \\
\hline \multirow[t]{3}{*}{4} & & 34 & 49 & $F$ & AML \\
\hline & & $25 \pm 6^{*}$ & $41 \pm 13 \dagger$ & & \\
\hline & Age-ma & d normoc & lar group & & \\
\hline 1 & & & 20 & $\mathrm{~F}$ & Nephrosis \\
\hline 2 & & & 27 & $\mathrm{~F}$ & Lymphadenitis \\
\hline 3 & & & 37 & M & Lymphadenitis \\
\hline 4 & & & 52 & M & Hyperthyroidism \\
\hline 5 & & & 68 & M & Amyloidosis \\
\hline 6 & & & 75 & M & COPD \\
\hline \multirow[t]{2}{*}{7} & & & 86 & $\mathrm{~F}$ & Lymphadenitis \\
\hline & & & $52 \pm 25 t$ & & \\
\hline
\end{tabular}

Patients were grouped based on the day their clots were sampled. The mean age of each group was not significantly different.

*Indicates the average days and SD after CBSCT in each group. Underlines indicate patients whose bone marrow specimens were obtained multiple times.

tIndicates the average age and SD in each group.

AML, acute myelogenous leukaemia; CBSCT, cord blood stem cell transplantation;

COPD, chronic obstructive pulmonary disease; days, sampling days; $F$, female; $M$,

male; MDS/AML, myelodysplastic syndrome overt AML.

statistical significance $(p=0.056$, figure $3 B)$. Meanwhile, the $\mathrm{CD} 68$-positive cell number seemed unaltered between the poor and the control groups (figure $3 \mathrm{~B}$ ).

\section{DISCUSSION}

Versican is an ECM molecule known to play an important role in cell adhesion, motility and immobilisation of humoral molecules. $^{2} 1828$ Moreover, versican participates intimately in the process of human diseases such as inflammation, atherosclerosis, cardiac infarction, and proliferation and invasion of cancer cells. $^{2428}$ Versican is a significant ECM molecule as mentioned; hence, it is important to determine the type of versicanproducing cells that are active at ECM of various normal and diseased tissues.

Several reports demonstrated that monocytes and macrophages, ${ }^{4} 14 \quad 15162930$ inflammatory cells, ${ }^{4}$ fibroblasts ${ }^{31}$ and myofibroblasts ${ }^{32}$ express versican. In many normal and disease tissues, however, cells that express versican are still not well established. Moreover, no reports so far have examined the cells in $\mathrm{BM}$, which is known to contain versican. ${ }^{21}$ These facts prompted us to delineate cell types that produce versican in $\mathrm{BM}$, while paying particular attention to tissue macrophages (see above). Using the single IHC method, we first stained the normocellular BM and observed that the anti-versican antibody appears to label macrophages. Then, applying double IHC using anti-versican and CD68 antibodies, we stained the same tissues and concluded that the major versican-expressing cells in BM are macrophages.

Macrophages are important players in the process of various diseases such as atherosclerosis, pneumonia, infectious diseases and progression of cancers. ${ }^{4}$ Moreover, macrophages are known to play an important role in BM regeneration. ${ }^{33-37}$ Meanwhile, versican functions as an important scaffold ECM molecule, and the haematopoietic restoration in transplanted BM appears to be regulated by proteoglycans of ECM and humoral factors. ${ }^{23}$ Therefore, we hypothesised that macrophage-derived versican may contribute to the regeneration process of BM after SCT for haematopoietic diseases.

Haematopoietic SCTs, BM, PB and CBSCT are performed as treatments for haematolymphoid neoplastic diseases including leukaemias and lymphomas. ${ }^{38}$ Clinically, cytarabine (CA) + cyclophosphamide (CY) +total body irradiation (TBI) (CA $+\mathrm{CY}+\mathrm{TBI}$ ) is generally performed in these transplantations as pretreatment to kill neoplastic cells as well as patients' haematopoietic cells ${ }^{26} 39$ and for the first few weeks, the total cell number in the BM declines. Then, blood SCs from donors are transfused to patients, engrafted and then start to produce progenitors such as neutrophils. They finally appear in PB, increase for 2-3 weeks and reach the normal level after approximately 40 days. An engraftment is defined by the number of neutrophils in the PB, which should be more than $500 / \mu \mathrm{L}$ for three continuous days.

We observed that around 10 days after transplantation the total number of haematopoietic cells in our patients' BM lowered to the minimum and recovered in number after 34 weeks, just as mentioned above. On the contrary, the number of versican-positive macrophages was sharply increased for 3 weeks, and then declined thereafter. This result demonstrated an inverse time course of the versican-positive macrophages to that of total cells in the transplanted BM. Meanwhile, the number of CD68-positive macrophages remained unaltered for the first 3 weeks unlike that of versican-positive macrophages, suggesting that not all macrophages but the versican-expressing ones play an important role in regeneration in this period. Given that versican contributes to BM regeneration in a positive fashion, it would be expected that the number of versicanpositive macrophages in BM of the poor engraftment cases is lower than that of fine engraftment cases. Although not statistically significant, we observed a clear trend of lowered versicanpositive cells in their BM. It requires more such cases in future. Macrophages are known to exist as resident cells in a steady state of $\mathrm{BM} .{ }^{27}$ It seems that residential macrophages, which are at first negative in versican expression, become versican-positive for the 3 weeks after transplantation. Perhaps the versican- 
Figure 1 Determination of versican-expressing cells in bone marrow specimens. (A) H\&E stain. ( $B$ and $C)$ Immunohistochemical stain with anti-versican (B) and anti-CD68 (C) antibodies, respectively, in the same bone marrow tissue. (D) Double immunohistochemical stain with anti-versican together with the anti-CD68 antibodies in bone marrow tissue. The most versican-positive cells (brown colour) are also CD68-positive (red colour) (open arrows). Nuclei were counterstained with haematoxylin. Original magnification for 3A-3D: $\times 1000$.

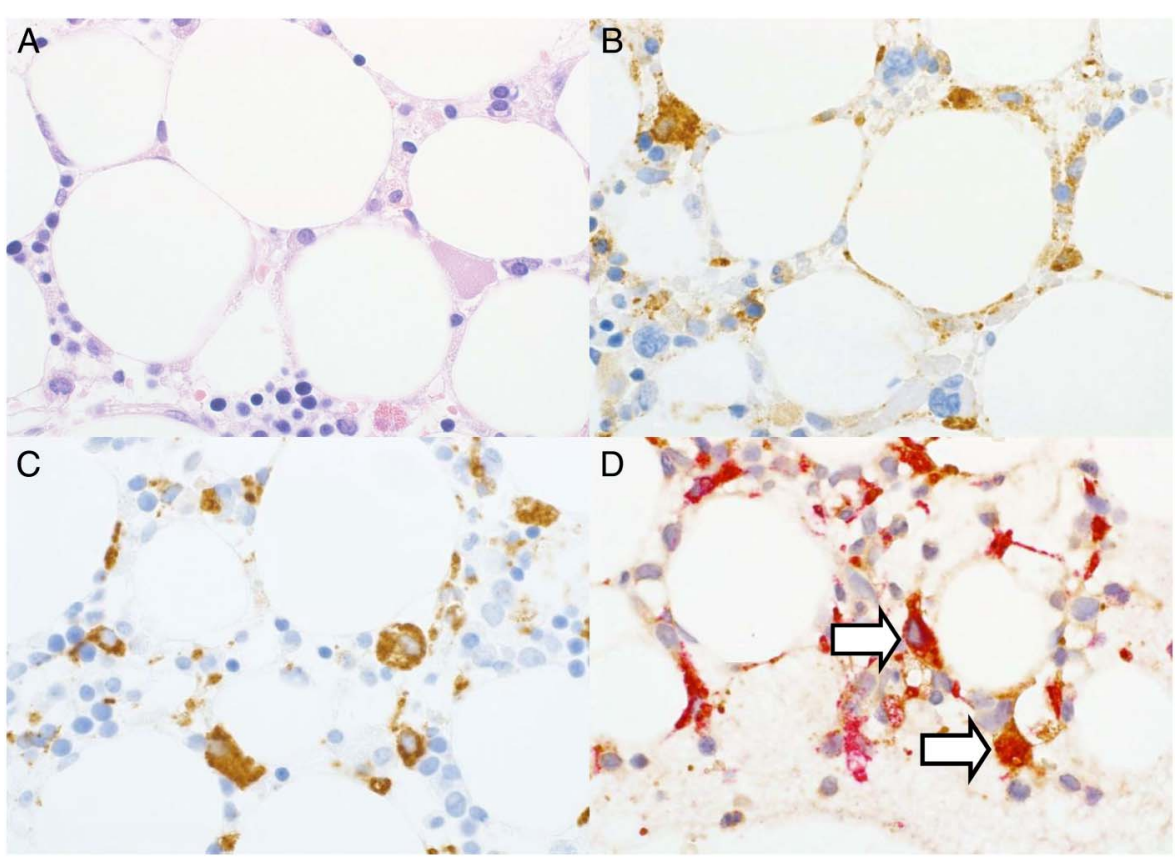

negative/CD68-positive macrophages start to express versican when BM is damaged by preconditioning and SCs are engrafted. In BM of multiple myeloma patients, after allogenic SCT, it becomes rich in chemokines and other humoral factors. ${ }^{40}$ Interestingly, versican can activate macrophages to upregulate tumour necrosis factor- $\alpha$ (TNF- $\alpha$ ) and interleukin-6 (IL-6). ${ }^{41}$ At least, in neuronal cells TNF- $\alpha$ induces versican expression. ${ }^{42}$ Perhaps, after preconditioning and CBSCT in BM, a positive feedback loop between versican and macrophage would be in function.
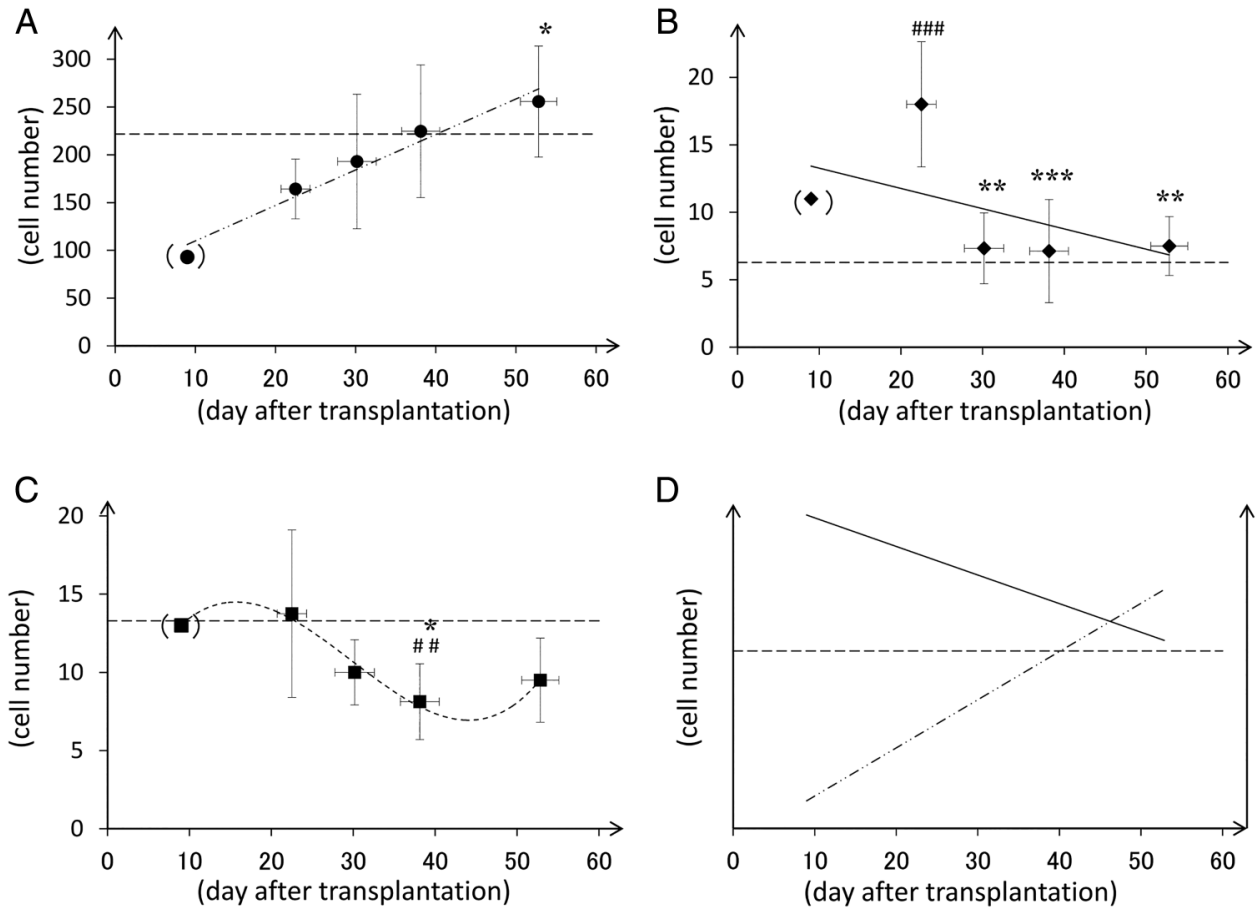

Figure 2 The average numbers and SD of the total (A), versican-positive (B) and CD68-positive cells (C) in a $0.15 \mathrm{~mm}^{2}$ area of bone marrow tissues. The dotted horizontal bars are an average of total, versican-positive and CD68-positive cells from the age-matched normocellular group. (A) *Indicates a significant difference between the 16-25 day and 46-55 day groups (analysis of variance, ${ }^{*} p<0.05$ ). Data were linearly well regressed $\left(r^{2}=0.962\right)$. (B) ${ }^{\# \# \# I n d i c a t e s ~ a ~ s i g n i f i c a n t ~ d i f f e r e n c e ~ b e t w e e n ~ t h e ~} 16$ and 25 day and the age-matched normocellular groups $\left({ }^{\# \# \#} p<0.001\right)$. ** and ${ }^{* * *}$ indicate a significant difference between the 16 and 25 day group and other three groups $\left({ }^{* *} p<0.01,{ }^{* *} p<0.001\right)$. Linear regression was applied as in $(A)\left(r^{2}=0.282\right)$. (C) ${ }^{\# \#}$ and * indicate a significant difference between the 36 and 45 day group and the age-matched normocellular group ( $\left.{ }^{\# \#} p<0.01\right)$ or $16-25$ day group $\left({ }^{*} p<0.05\right)$, respectively. A polynomial curve was well regressed $\left(r^{2}=0.974\right)$. (D) A schematic presentation of the versican-positive macrophage (closed line) in reference to the total cells (dotted line). Their corresponding baselines from the age-matched normocellular group were overlayered. 

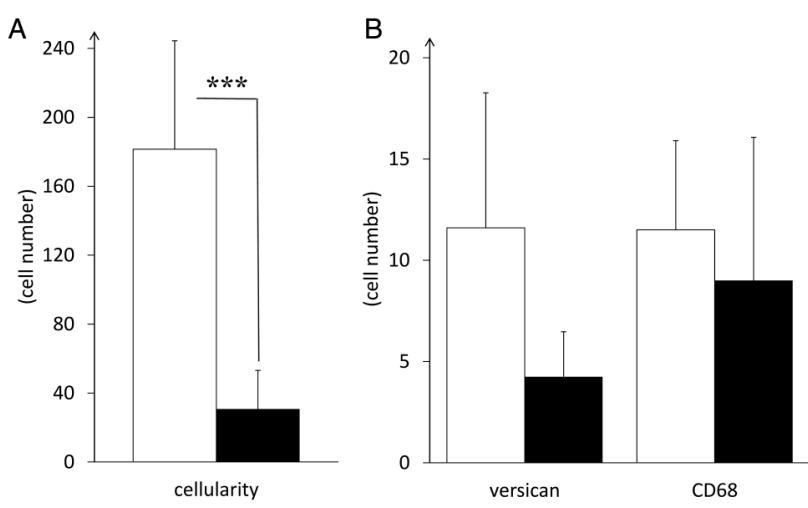

Figure 3 Comparison of the total cell numbers $(A)$, versican-positive $(B$, left) and CD68-positive cells ( $B$, right) of the age-matched and sampling day-matched patients group (open bar) with those of the age-matched poor engraftment group (closed bar). *Indicates a significant difference (t test, $\left.{ }^{* * *} \mathrm{p}<0.001\right)$. Versican-positive macrophages are approximately half that of the control, yet it does not reach statistical significance $(p=0.056)$.

Although the underlying mechanism behind versican's contribution to BM regeneration is not clear, given that versican serves as a scaffold molecule that binds several serological factors such as chemokines ${ }^{18}$ and midkines, ${ }^{19}$ it is likely that versican at the BM stroma binds humoral factors such as granulocyte-colony-stimulating factor. In fact, in our hospital and in many others, it is perfused on the +7 day of transplantation to aid progenitors so as to be differentiated into neutrophils.

Another intriguing unsolved question is the origin of macrophages after CBSCT. Given that versican presets a favourable environment in the BM for donors' SCs, they should not be eliminated by preconditioning. Comparison of BM clots just before and after preconditioning will be essential to determine the hypothesis above. The use of sex-determining in situ hybridisation on the clot specimens of patients who received CBSCT from sex-unmatched donor should also be performed in future.

In this report, we demonstrated that the predominant versican-expressing cells in $\mathrm{BM}$ are macrophages, and evaluated a time course of the number of versican-positive macrophages in BM after CBSCT. Our results suggest that versican and/or versican-expressing macrophages have important roles in $\mathrm{BM}$ regeneration by establishing a supportive environment at its ECM for transplanted SCs to be engrafted. We are preparing several more cases of AML with CBSCT and will analyse them in the near future. Moreover, in vivo and in vitro experiments on versican induction in macrophages of BM should further be performed to establish the present analysis on human samples.

\section{Take home messages}

- Versican is produced by macrophages in bone marrow as in many other tissues.

- In bone marrow of patients with acute myelogenous leukaemia after cord blood stem cell transplantation (CBSCT), the number of versican-positive macrophages is inversely correlated to that of total cells.

- Versican seems to play an important role in bone marrow regeneration after $\mathrm{CBSCT}$.
Handling editor Mary Frances McMullin

Acknowledgements We thank our staff at the department of clinical laboratory and haematology of Konan Kosei Hospital for their kind help in analysing patient bone marrow. We also express our appreciation to Akio Kohno, Keiji Funahashi and Naoyuki Sumiyoshi of Konan Kosei Hospital for the technical support of this research.

Contributors MS, RF and TN designed the study. MS and RF performed experiments and analysis on clinical data. MS, RF and TN wrote the paper.

Funding This work was supported in part by the funding from the Konan Kosei Hospital.

Competing interests None declared.

Ethics approval Nagoya University Ethical Committee.

Provenance and peer review Not commissioned; externally peer reviewed.

Open Access This is an Open Access article distributed in accordance with the Creative Commons Attribution Non Commercial (CC BY-NC 4.0) license, which permits others to distribute, remix, adapt, build upon this work non-commercially, and license their derivative works on different terms, provided the original work is properly cited and the use is non-commercial. See: http://creativecommons.org/ licenses/by-nc/4.0/

\section{REFERENCES}

1 Wight TN. Versican: a versatile extracellular matrix proteoglycan in cell biology. Curr Opin Cell Biol 2002;14:617-23.

2 Theocharis AD. Versican in health and disease. Connect Tissue Res 2008;49: 230-4.

3 Ricciardelli C, Sakko AJ, Ween MP, et al. The biological role and regulation of versican levels in cancer. Cancer Metastasis Rev 2009;28:233-45.

4 Wight TN, Kang I, Merrilees MJ. Versican and the control of inflammation. Matrix Biol 2014;35:152-61.

5 Cöster L, Carlstedt I, Malmström A. Isolation of 35S- and 3H-labelled proteoglycans from cultures of human embryonic skin fibroblasts. Biochem J 1979;183:669-81.

6 Evanko SP, Angello JC, Wight TN. Formation of hyaluronan- and versican-rich pericellular matrix is required for proliferation and migration of vascular smooth muscle cells. Arterioscler Thromb Vasc Biol 1999;19:1004-13.

7 Evanko SP, Johnson PY, Braun KR, et al. Platelet-derived growth factor stimulates the formation of versican-hyaluronan aggregates and pericellular matrix expansion in arterial smooth muscle cells. Arch Biochem Biophys 2001;394:29-38.

8 Matsumoto K, Kamiya N, Suwan K, et al. Identification and characterization of versican/PG-M aggregates in cartilage. J Biol Chem 2006;281: 18257-63.

9 Zimmermann DR, Dours-Zimmermann MT, Schubert M, et al. Versican is expressed in the proliferating zone in the epidermis and in association with the elastic network of the dermis. J Cell Biol 1994;124:817-25.

10 Bode-Lesniewska B, Dours-Zimmermann MT, Odermatt BF, et al. Distribution of the large aggregating proteoglycan versican in adult human tissues. J Histochem Cytochem 1996;44:303-12.

11 Sobue M, Nakashima N, Fukatsu T, et al. Production and immunohistochemical characterization of a monoclonal antibody raised to proteoglycan purified from a human yolk sac tumour. Histochem J 1989:21:455-60.

12 Isogai Z, Shinomura T, Yamakawa N, et al. 2B1 antigen characteristically expressed on extracellular matrices of human malignant tumors is a large chondroitin sulfate proteoglycan, PG-M/versican. Cancer Res 1996;56:3902-8.

13 Kimata K, Oike Y, Tani K, et al. A large chondroitin sulfate proteoglycan (PG-M) synthesized before chondrogenesis in the limb bud of chick embryo. J Biol Chem 1986;261:13517-25.

14 Toeda K, Nakamura K, Hirohata S, et al. Versican is induced in infiltrating monocytes in myocardial infarction. Mol Cell Biochem 2005;280:47-56.

15 Chang MY, Tanino Y, Vidova V, et al. Reprint of: a rapid increase in macrophage-derived versican and hyaluronan in infectious lung disease. Matrix Biol 2014;35:162-73

16 Sotoodehnejadnematalahi F, Staples KJ, Chrysanthou E, et al. Mechanisms of hypoxic up-regulation of versican gene expression in macrophages. PLOS ONE 2015;10:e0125799.

17 Yamagata M, Yamada KM, Yoneda $\mathrm{M}$, et al. Chondroitin sulfate proteoglycan (PG-M-like proteoglycan) is involved in the binding of hyaluronic acid to cellular fibronectin. J Biol Chem 1986;261:13526-35.

18 Hirose J, Kawashima H, Yoshie 0, et al. Versican interacts with chemokines and modulates cellular responses. J Biol Chem 2001;276:5228-34.

19 Zou K, Muramatsu H, lkematsu S, et al. A heparin-binding growth factor, midkine, binds to a chondroitin sulfate proteoglycan, PG-M/versican. Eur J Biochem 2000;267:4046-53. 
20 Nagasaka T, Sobue M, Niwa M, et al. Effects of $\beta$-D-xylosides on proliferation and matrix formation of adherent fibroblastic cells in mouse bone marrow culture. Exp Hematol 1989;17:923-8.

21 Nagasaka T, Nakashima N, Sumiyoshi N, et al. Myxomatous stromal changes in bone marrow following chemotherapy for acute leukemia-immunohistochemical characteristic of matrix components. Rinsho Byori 1990;38:1358-62.

22 Oguri $\mathrm{K}$, Okayama $\mathrm{E}$, Caterson $\mathrm{B}$, et al. Isolation characterization, and localization of glycosaminoglycans in rabbit bone marrow. Blood 1987;70:501-10.

23 Wu YJ, La Pierre DP, Wu J, et al. The interaction of versican with its binding partners. Cell Res 2005;15:483-94.

24 Eapen M, Rubinstein P, Zhang MJ, et al. Outcomes of transplantation of unrelated donor umbilical cord blood and bone marrow in children with acute leukaemia: a comparison study. Lancet 2007;369:1947-54.

25 Eapen M, Rocha V, Sanz G, et al. Effect of graft source on unrelated donor haemopoietic stem-cell transplantation in adults with acute leukaemia: a retrospective analysis. Lancet Oncol 2010;11:653-60.

26 Arai Y, Takeda J, Aoki K, et al. Efficiency of high-dose cytarabine added to CY/TBI in cord blood transplantation for myeloid malignancy. Blood 2015;126:415-22.

27 Lau SK, Chu PG, Weiss LM. CD163: a specific marker of macrophages in paraffin-embedded tissue samples. Am J Clin Pathol 2004;122:794-801.

28 Du WW, Yang W, Yee AJ. Roles of versican in cancer biology-tumorigenesis, progression and metastasis. Histol Histopathol 2013;28:701-13.

29 Chang MY, Olin KL, Tsoi C, et al. Human monocyte-derived macrophages secrete two forms of proteoglycan-macrophage colony-stimulating factor that differ in their ability to bind low density lipoproteins. J Biol Chem 1998;273:15985-92.

30 Asplund A, Stillemark-Billton P, Larsson E, et al. Hypoxic regulation of secreted proteoglycans in macrophages. Glycobiology 2010;20:33-40.

31 Zimmermann DR, Ruoslahti E. Multiple domains of the large fibroblast proteoglycan, versican. EMBO J 1989;8:2975-81.
32 Hattori N, Carrino DA, Lauer ME, et al. Pericellular versican regulates the fibroblast-myofibroblast transition: a role for ADAMTS5 protease-mediated proteolysis. J Biol Chem 2011;286:34298-310.

33 Mayani H, Guilbert LJ, Janowska-Wieczorek A. Biology of the hemopoietic microenvironment. Eur J Haematol 1992;49:225-33.

34 Wilson JG, Tavassoli M. Microenvironmental factors involved in the establishment of erythropoiesis in bone marrow. Ann N Y Acad Sci 1994;718:271-83; discussion 283-4.

35 Domenech J, Roingeard F, Hérault 0 , et al. Changes in the functional capacity of marrow stromal cells after autologous bone marrow transplantation. Leuk Lymphoma 1998;29:533-46.

36 Thiele J, Kvasnicka HM, Beelen DW, et al. Bone marrow engraftment: histopathology of hematopoietic reconstitution following allogeneic transplantation in CML patients. Histol Histopathol 2001;16:213-26.

37 Winkler IG, Sims NA, Pettit AR, et al. Bone marrow macrophages maintain hematopoietic stem cell (HSC) niches and their depletion mobilizes HSCs. Blood 2010:116:4815-28

38 Copelan EA. Hematopoietic stem-cell transplantation. N Engl J Med 2006:354:1813-26.

39 Copelan EA, Hamilton BK, Avalos B, et al. Better leukemia-free and overall survival in $\mathrm{AML}$ in first remission following cyclophosphamide in combination with busulfan compared with TBI. Blood 2013:122:3863-70.

40 Cao Y, Luetkens T, Kobold S, et al. The cytokine/chemokine pattern in the bone marrow environment of multiple myeloma patients. Exp Hematol 2010;38: $860-7$

41 Kim S, Takahashi H, Lin WW, et al. Carcinoma-produced factors activate myeloid cells through TLR2 to stimulate metastasis. Nature 2009;457:102-6.

42 Gu WL, Fu SL, Wang YX, et al. Expression and regulation of versican in neural precursor cells and their lineages. Acta Pharmaco/ Sin 2007;28:1519-30. 